Boise State University

ScholarWorks

Psychological Sciences Faculty Publications and

Presentations

Department of Psychological Science

4-1-2014

Do Body Image Investment and Evaluation Relate to Bulimic Symptoms in U.S. Collegiate Men and Women in the Same Way?

Mary E. Pritchard

Boise State University 


\title{
Do Body Image Investment and Evaluation Relate to Bulimic Symptoms in U.S. Collegiate Men and Women in the Same Way?
}

\author{
Mary E. Pritchard \\ Department of Psychology \\ Boise State University \\ Marypritchard@boisestate.edu
}

\begin{abstract}
Although research suggests that body image investment (i.e., drive for muscularity, orientation toward appearance, preoccupation with weight or weight gain) and body image evaluation factors (e.g., negative evaluations of appearance, overestimation of current weight) correlate with bulimic symptoms, the magnitude of these relationships may differ between men and women. The relationship between bulimic symptoms and the drive for muscularity, one form of body image investment theorized to be particularly relevant to men, is understudied in college students. This study examined bulimic symptoms, body image investment, and body image evaluation in American undergraduate students (84 men, 198 women). Bulimic symptoms were negatively associated with appearance evaluation and positively associated with appearance orientation, weight preoccupation and weight overestimation in both men and women. Bulimic symptoms were positively associated with the drive for muscularity in men, but not in women. Awareness of the relationships between bulimic symptoms and body image investment and evaluation may help identify those at risk for bulimic symptoms.
\end{abstract}

Keywords: sex, bulimic symptoms, the drive for muscularity, body image investment, body image evaluation

Bulimia nervosa is an eating disorder characterized by recurrent binge eating, followed by compensatory behaviors such as purging, fasting, the use of laxatives, enemas, diuretics, and over exercising to burn excess calories (American Psychiatric Association, APA, 2000). Bulimia nervosa can lead to a variety of health risks, including damage to dental enamel and gum tissue (Mehler, 2011; Pomery \& Mitchell, 2001), gastro-intestinal problems (Mehler, 2011; Pomery \& Mitchell, 2001), and death (Crow et al., 2009). Although eating disorders have long been perceived to occur primarily in women, $10-20 \%$ of all patients with bulimia nervosa are men (Joiner, Katz, \& Heatherton, 2000; Jones \& Morgan, 2010).

Research on men with bulimia nervosa is sparse; however, recent studies indicate the number of men suffering from the disorder may be greater than previously thought (Herpertz, Kocnar, \& Senf, 1997; Jones \& Morgan, 2010). This may be due to changes in the perception that eating disorders only affect women (Herpertz et al., 1997; Jones \& Morgan, 2010) and homosexual men (Jones \& Morgan, 2010), or an actual increase in the number of men who are suffering from eating disorders (Morgan, 2009). Regardless, the number of men who are dissatisfied with their bodies and are taking steps to reduce their dissatisfaction is increasing (Morgan, 2009; Ryan \& Morrison, 2009).

When assessing body image, researchers typically focus on two dimensions: body image investment and body image evaluation (Cash, Melnyk, \& Hrabosky, 2004). Body image investment reflects the degree of cognitive and behavioral importance that someone assigns to his or her body and appearance, whereas body image evaluation is a person's satisfaction or dissatisfaction with his or her appearance (Cash et al., 2004). Research suggests an increase in both body image investment and body image evaluation in young men in recent years (Ryan \& Morrison, 2009, 2011). Morgan (2009, n.p.) attributes this to "a crisis of masculinity in our society," and notes that media images of lean and muscular men are at the root of men's increasing body dissatisfaction and manipulation (e.g., diet, exercise). That is, the more men report internalizing societal pressures to obtain the ideal male body shape and size, the more likely they are to report negative body image investment including appearance orientation (i.e., checking themselves in the mirror) and fear of becoming fat, as well as negative body image evaluation including lower selfevaluations of their appearance (i.e., negative evaluations of one's own appearance) and overestimation of weight 
This is an author-produced, peer-reviewed version of this article. The final, definitive version of this document can be found online at Psychology of Men \& Masculinity, published by the American Psychological Association Copyright restrictions may apply. doi: 10.1037/a0032835

(Finlayson, Kelly, \& Saklofske, 2002; McCabe, Ricciardelli, Sitaram, \& Mikhail, 2006; Petrie, Greenleaf, Carter, \& Reel, 2007; see Chernyak \& Lowe, 2010; Petrie, Greenleaf, Reel, \& Carter, 2009; Spoor, Bekker, Van Heck, Croon, \& Van Strien, 2005, for similar results in women). Men who report internalizing societal pressures are also more likely to report symptoms of anorexia nervosa and symptoms of bulimia nervosa including binge eating, purging and other compensatory behaviors such as excessive exercise and diuretic or laxative use, perceived loss of control over eating, over concern with body weight and shape (Finlayson et al., 2002; Leone, Sedory, \& Gray, 2005; McCabe \& McGreevy, 2011; Petrie et al., 2007; Tong et al., 2005; see Petrie et al., 2009; Spoor et al., 2005, for similar results in women).

Although societal pressures are associated with negative body image investment, body image evaluation, and bulimic symptoms in both men and women, negative body image investment seems to manifest itself differently in men and women. Whereas research suggests that women may be more concerned with their level of body fat (Chernyak \& Lowe, 2010), research indicates that men are more likely to be concerned with both their level of body fat and their level of muscularity (Jung, Forbes, \& Chan, 2010). In particular, the current ideal male body is both lean (having low body fat) and muscular, with a well-developed chest and arms, wide shoulders and a narrow waist (Hargreaves \& Tiggemann, 2004). This desire for a larger, more muscular ideal body image has become known as the drive for muscularity (McCreary \& Sasse, 2000). Normal-weight men are now displaying the desire to be more muscular and bulky, and are dieting to gain muscle in their upper bodies and tone their abdominal muscles (McCreary, Sasse, Saucier, \& Dorsch, 2004). Although studies of competitive and recreational bodybuilders (Goldfield, Blouin, \& Woodside, 2006; Hallsworth, Wade, \& Tiggemann, 2005) and male collegiate athletes (Petrie at al., 2007) suggest that men who desire to increase their muscularity may engage in bulimic behaviors to achieve this goal, no studies of college students have examined whether this relation between the drive for muscularity and bulimic symptomology is common among male non-bodybuilders and non-athletes or among women.

\section{Present Study}

Previous research suggests body image evaluation (i.e., negative evaluations of one's appearance, overestimation of body weight) and body image investment (i.e., appearance orientation, preoccupation with becoming overweight/fat) may relate to bulimic symptoms in both men and women. However, as most studies have examined men or women, no studies have examined whether the magnitude of the relationships between negative body image investment, body image evaluation, and bulimic symptoms may differ between men and women. In addition, no studies have examined whether negative body image investment in the form of the drive for muscularity is associated with bulimic symptoms in women or non-athlete collegiate men. Finally, given the sex differences in body image goals (e.g., Chernyak \& Lowe, 2010; Jung et al., 2010), it makes sense that there may be sex differences in relationships between negative body image evaluation factors and bulimic symptomology. For example, women may be more likely to use bulimic behaviors as a way to avoid becoming fat (Chernyak \& Lowe, 2010), whereas men may be more likely to use bulimic behaviors as part of their drive to become more muscular (Petrie at al., 2007). However, no studies have examined whether sex moderates the relation between bulimic symptoms and negative body image investment and body image evaluation in collegiate men and women.

In sum, the purpose of the present study was to: 1) to examine whether the magnitude of the relationships between negative body image evaluation (i.e., negative evaluations of one's appearance, overestimation of body weight), negative body image investment (i.e., appearance orientation, preoccupation with becoming overweight/fat, the drive for muscularity), and bulimic symptoms differed between men and women, 2) investigate whether the littleresearched body image investment factor drive for muscularity is associated with bulimic symptoms in male and female college students, and 3) to examine whether sex moderated the relation between bulimic symptomology and negative body image investment (i.e., appearance orientation, preoccupation with becoming overweight/fat, the drive for muscularity) or negative body image evaluation (i.e., negative evaluations of one's appearance, overestimation of body weight).

We hypothesized that negative body image investment (i.e., appearance orientation, preoccupation with becoming overweight/fat) and negative body image evaluation (i.e., negative evaluations of one's appearance, overestimation of body weight) would be positively associated with bulimic symptoms in both men and women. In addition, given the relationship between negative body image investment as measured by the drive for muscularity and bulimic symptoms in male collegiate athletes (Petrie at al., 2007), we hypothesized that the same would be true for all male college students; that is, we hypothesized that the drive for muscularity would correlate positively with bulimic 
This is an author-produced, peer-reviewed version of this article. The final, definitive version of this document can be found online at Psychology of Men \& Masculinity, published by the American Psychological Association Copyright restrictions may apply. doi: 10.1037/a0032835

symptomology in collegiate men. No specific hypotheses were made for female college students as no studies have examined the relationship between bulimic symptomology and the drive for muscularity in that population. However, as 78\% of women report wanting to be more muscular (Jacobi \& Cash, 1994) and, in fact, sex difference in the drive for muscularity vanish when the focus is on "tone" rather than bulk (Kyrejto, Mosewich, Kowalski, Mack, \& Crocker, 2008), we felt it was important to examine possible associations between the drive for muscularity and bulimic symptomology in women. Finally, we hypothesized that sex would moderate any relationships between bulimic symptomology, negative body image investment, and negative body image evaluation.

\section{Method}

\section{$\underline{\text { Participants }}$}

American undergraduate (104 men, 219 women) Introductory Psychology students participated in this study as one of several options for course credit. Because research indicates that body image investment may differ between college-age students and adults (Green \& Pritchard, 2003; Spann \& Pritchard, 2010), participants over the age of 25 were eliminated to ensure the population was of a traditional college student age. The final sample included 282 participants (84 men, 198 women). Most men self-identified as Caucasian (86.9\%), followed by African American (3.6\%), Latino (4.8\%), Asian American (2.4\%), Native American (1.2\%), and other (1.2\%). Most women also selfidentified as Caucasian (87.3\%), followed by Latino (5.1\%), other (3.0\%), Asian American (2.5\%), Pacific Islander (1.0\%), African American (0.5\%), and Native American (0.5\%). There were no significant sex differences in race, $\chi^{2}(\mathrm{df}=6, \mathrm{~N}=281)=5.95$. Men were significantly older (range: 18 to $25, M=19.87$ years, $S D=2.19$ ) than were women (range: 18 to $25, M=18.97$ years, $S D=1.88$ ), $t(280)=3.50, p<.001$. Thus, age was controlled for in all analyses. The Boise State University Institutional Review Board approved the study prior to data collection.

\section{$\underline{\text { Measures }}$}

Body image evaluation. The 34-item Multidimensional Body-Self Relations Questionnaire (MBSRQ) -Appearance Scales (Cash, 2000) assess body image evaluation as well as body image investment. The scale was designed for use in both male and female populations and research suggests that this measure is valid and reliable in both male and female college student populations (Clark et al., 2005; Izgiç, Akyüz, Doğan, \& Kuğu, 2004). For confirmation of factor structures, please see Brown, Cash, and Mikulka (1990). The MBSRQ-AS measures the following body evaluation subscales (internal consistency measures for the present study are presented in parentheses following each subscale sample item): self-classified weight (2 items; e.g., "I think I am... 1=very underweight; $5=v e r y$ overweight"; $r_{\text {overall }}=.67 ; r_{\text {women }}=.67 ; r_{\text {men }}=.69$ ), and appearance evaluation (7 items; e.g., "Most people would consider me good looking"; $1=$ definitely disagree; $5=$ definitely agree; $\alpha_{\text {overall }}=.89 ; \alpha_{\text {women }}=.88 ; \alpha_{\text {men }}=.89$ ). Items for each subscale are averaged, with higher scores indicating more of that type of body image evaluation.

Body image investment. For the purposes of the present study, body image investment was measured using three scales. First, two measures of body image investment from the MBSRQ -AS (Cash, 2000) were used: overweight preoccupation (4 items; e.g., "I am very conscious of even small changes in my weight"; $1=$ definitely disagree; $5=$ definitely agree; $\alpha_{\text {overall }}=.79 ; \alpha_{\text {women }}=.79 ; \alpha_{\text {men }}=.75$ ), appearance orientation (12 items; e.g., "I check my appearance in a mirror whenever I can"; $\left.\alpha_{\text {overall }}=.83 ; \alpha_{\text {women }}=.86 ; \alpha_{\text {men }}=.84\right)$. Next, the 15-item Drive for Muscularity Scale (McCreary \& Sasse, 2000) was used to measure the drive for muscularity. Although the scale was developed to assess body dissatisfaction in men and boys, it was originally tested in male and female high school students (McCreary \& Sasse, 2000), and has been shown to be valid and reliable in collegiate men and women (Wojtowicz \& von Ranson, 2006). Participants respond to statements about their desired muscularity (e.g., "I think that I would look better if I gained 10 pounds in bulk," and "I think that I would feel stronger if I gained a little more muscle mass") on a 6 -point Likert scale $(1=$ never, $2=$ rarely, $3=$ sometimes, $4=$ often, $5=$ very often, $6=$ always $)$. Scores are averaged into an overall mean $\left(\alpha_{\text {overall }}=.88, \alpha_{\text {women }}=.84, \alpha_{\text {men }}=.88\right.$, for the present study), with higher scores indicating higher levels of the drive for muscularity.

Bulimic symptoms. The 36-item Bulimia Test (BULIT; Smith \& Thelen, 1984) assesses bingeing behaviors, purging behaviors, feelings following eating binges, types of food preferred during binges and weight fluctuations. This test asks about the participant's eating patterns (e.g., "My eating patterns are different from the eating patterns of most people"), their feelings towards eating (e.g., "I feel sad or blue after eating more than I had planned to eat"), and 
how they feel about themselves (e.g., "I don't like myself after I eat too much”). The response options differ among the questions. Items are summed to create a scale score $\left(\alpha_{\text {overall }}=.93 ; \alpha_{\text {women }}=.93 ; \alpha_{\text {men }}=.93\right.$, in the present study), with higher scores indicating higher levels of bulimic symptomology, where 85 is considered the cutoff for bulimic behavior (Fischer \& Corcoran, 2007). Although the BULIT was originally designed to screen for bulimic symptoms in women, research suggests that the BULIT is a valid and reliable indicator of bulimic symptoms in both men and women (Arévalo et al., 2005; Arévalo, Aguilar, Rayón, Paredes, \& Díaz, 2004; Dallard, Cathebras, Sauron, \& Massoubre, 2001; Thelen, Farmer, Mann, \& Pruitt, 1990).

\section{Results}

Before testing our first hypothesis, we first wanted to ascertain whether or not there were sex differences in any of our key variables. To this end, we conducted a MANOVA using age as the covariate. The overall model was significant for both age, $F(6,266)=2.13, p \leq .05, \eta^{2}=.05$, and gender, $F(6,266)=25.32, p<.001, \eta^{2}=.36$. Means, standard deviations, and ranges of all measures reported by sex are presented in Table 1 . Scores on the BULIT were comparable for men and women, with six (7.14\%) of the men meeting the cutoff and $16(8.2 \%)$ of the women meeting the cutoff for bulimic behavior on the BULIT. Men evidenced a stronger drive for muscularity, whereas women displayed higher self-classified weights, overweight preoccupation, and the appearance orientation aspect of body image investment (see Table 1).

Correlations between all measures separated by sex are reported in Table 2. As hypothesized, bulimic symptoms correlated negatively with both measures of body image evaluation: negative appearance evaluation and selfclassified weight (participants were more likely to describe themselves as overweight). Thus, men and women who rated higher on bulimic symptomology rated themselves lower on their perceptions of their appearance. In addition, as hypothesized, men and women who scored higher on bulimic symptomology also reported more pathological levels of two of the measures of body image investment, including appearance orientation (focus on one's appearance) and overweight preoccupation (fear of becoming fat). In addition, men who scored higher on the drive for muscularity also scored higher on the BULIT, as hypothesized. However, no relationship was found between the drive for muscularity and bulimic symptoms in women.

To examine whether the magnitude of correlations between body image investment factors and bulimic symptoms differed for men and women, we statistically compared the correlations between bulimic symptoms and each of the body image investment factors for men and women using Fisher's (1921) r-to-Z transformation. The correlation between the drive for muscularity and bulimic symptomology was significantly greater in men than in women, $Z=$ 2.39, $p=.009$. However, there were no differences between men and women in the correlation between bulimic symptoms and overweight preoccupation, $Z=1.85$, self-classified weight category, $Z=-.43$, appearance evaluation, $Z=-1.93$, or appearance orientation, $Z=.17$.

We had hypothesized that sex would moderate any relationships between bulimic symptomology, body image investment, and body image evaluation. To this end, hierarchical regression analyses were conducted, in accordance with Baron and Kenny's (1986) theory on moderation models. All variables were examined for skewness and kurtosis to ensure normality and all factors were centered. Partial correlations, tolerance, VIF, and minimum tolerance statistics were also examined and no indices of multicollinearity were found. The factors were entered in three blocks in a hierarchical regression model: First, we entered our demographic variables: age and sex. Next, we entered the body image investment (overweight preoccupation, appearance orientation, and the drive for muscularity) and body image evaluation factors (self-classified weight, appearance evaluation). Finally, we entered the interactions between sex and all body image investment and evaluation factors (see Table 3).

Sex and age were first entered in the regression analysis to account for the variability in bulimic symptomology. Neither variable contributed significantly to the model. Next, the body image investment and evaluation factors were entered into the equation. These factors were strongly predictive and accounted for $28 \%$ of the variance in bulimic symptomology. In particular, preoccupation with weight or weight gain, negative evaluations of one's appearance, and the drive for muscularity were significantly related to bulimic symptoms. In the final step of the analysis, we tested the moderating effect of sex on the relationship between body image factors and bulimic symptomology. The interactions did not contribute a significant amount to the explanation of bulimic symptomology. Thus, no moderation was found (see Table 3). 
This is an author-produced, peer-reviewed version of this article. The final, definitive version of this document can be found online at Psychology of Men \& Masculinity, published by the American Psychological Association Copyright restrictions may apply. doi: $10.1037 / \mathrm{a} 0032835$

\section{Discussion}

The purpose of the present study was to: 1) to examine whether the magnitude of the relationships between body image evaluation, body image, investment, and bulimic symptoms differed between men and women, 2) investigate whether body image investment as measured by the drive for muscularity associated with bulimic symptoms in male and female college students, and 3) to examine whether sex moderated the relation between bulimic symptomology and body image investment or body image evaluation.

As hypothesized, the drive for muscularity was more strongly related to bulimic symptomology in men than in women in the present study (Petrie at al., 2007). Given previous research suggesting that male bodybuilders and male collegiate athletes may engage in binging and purging or other compensatory behaviors to help meet their muscularity goals (Goldfield et al., 2006; Hallsworth et al., 2005; Petrie at al., 2007), one purpose of the present study was to examine whether this relationship held in a non-athlete college population. Our results suggest that non-athlete male college students may also engage in such behaviors to meet muscularity goals. Another purpose of this study was to examine the relationship between bulimic symptoms and the drive for muscularity in women. Given the sex differences in body image concerns (e.g., Chernyak \& Lowe, 2010; Jung et al., 2010), we wondered whether bulimic symptoms would correlate with body image investment and evaluation in the same way in men and women. The drive for muscularity did not correlate with bulimic symptoms in women. This may be because women tend to be less concerned with their muscularity and more concerned with losing weight via restrictive dieting or skipping meals (e.g., drive for thinness rather than the drive for muscularity; Chernyak \& Lowe). Future research should further examine this relationship between the drive for muscularity and bulimic symptoms in both men and women. Perhaps there are other characteristics besides sex that influence whether a relationship between these two variables exists. For example, gender role orientation has been shown to relate to symptoms of disordered eating in men and women (Pritchard, 2008); perhaps gender role orientation would also influence the drive for muscularity. In addition, future research may wish to investigate how drive for thinness factors into the equation.

The final purpose of this study was to investigate whether sex moderates the relationships among negative body image investment, negative body image evaluation, and bulimic symptoms in collegiate men and women. This hypothesis was not supported. No interactions existed between sex and body image investment or evaluation in relation to bulimic symptoms. Rather, preoccupation with weight and weight gain was strongly related to bulimic symptoms in both male and female college students. Although this relationship was expected (Chernyak \& Lowe, 2010; Petrie et al., 2007; Tong et al., 2005), the strength of the relationship between this body image investment factor and bulimic symptoms was interesting to note and should be investigated further. For example, it is possible that preoccupation with weight gain may relate to drive for thinness and anorexic-like symptoms more so than it does bulimic symptoms. In addition, appearance evaluation was related to bulimic symptoms in both men and women. Again, while this relationship was expected (Finlayson et al., 2002; Petrie et al., 2007; Petrie et al., 2009; Spoor et al., 2005), the fact that appearance evaluation, in combination with overweight preoccupation, seemed more strongly related to bulimic symptoms than were other body image factors was intriguing and should be explored further. It does seem intuitive that those engage in behaviors to modify their weight would be focused on weight and weight gain as well as appearance; however, it is unclear why they would not also be focused on their perceptions of their weight or be oriented more toward their appearance and the appearance of others. Future studies should examine this question.

Several limitations that may hinder generalizability should be addressed. First, participants were primarily Caucasian. Further research should investigate whether these findings hold in a more diverse sample. Second, we used the BULIT (Smith \& Thelen, 1984) instead of the BULIT-R (Thelen, Farmer, Wonderlich, \& Smith, 1991) because it had more use and support as a valid measure of bulimic symptoms in men than did newer versions of the BULIT. Results may differ with use of the BULIT-R. Future research may wish to utilize patients with clinically diagnosable bulimia nervosa to better investigate the factors that influence bulimic symptomology. The internal consistency for self-classified weight was lower than desired. As the scale only consisted of two items, this was not completely unexpected, but future research may wish to use a different scale to measure self-classified weight. Finally, the present study's sample consisted of college students only. Additional studies using clinical populations may be warranted to inform the clinical work of mental health professionals. 
Despite these limitations, our findings do contribute to the literature overall. Although body image investment factors clearly relate to bulimic symptoms in both men and women, the role of the drive for muscularity seems to have a greater impact on men's than on women's bulimic symptomology. Overall awareness of the relationships between bulimic symptoms and body image investment and evaluation will help the greater population educate individuals on the potential risk factors for bulimic symptoms. In addition, universities may wish to increase campus and community awareness regarding body image investment, evaluation, and bulimic symptoms. Finally, when treating men or women suffering from bulimia nervosa, counselors and therapists may want to focus on the client's preoccupation with weight and weight gain and the client's views about his or her own appearance. Counselors may also wish to discuss the drive for muscularity with their male clients as male clients may be mistakenly thinking that binge and purge behaviors will help them pack on muscle without adding fat.

\section{References}

American Psychiatric Association (2000). Diagnostic and statistical manual of mental disorders DSM-IV-TR (4th ed.). American Psychiatric Publishing, Washington, DC.

Arévalo, R., Aguilar, X., Rayón, G., Paredes, K., \& Díaz, J. (2004). Presence of eating disorders in Mexican men and women: Some associated factors. Psicología Conductual Revista Internacional de Psicología Clínica de la Salud, 12, 415-427. doi: 10.1037/t06040-000

Arévalo, R., Díaz, J., González, C., Aguilar, X., Rayón, G., Martínez, A., \& Paredes, K. (2005). Eating disorders and risk factors in an incidental sample of young Mexicans. Revista Mexicana de Psicología, 22, 53-63. doi: 10.1037/t06040-000

Baron, R. M., \& Kenny, D. A. (1986). The moderator-mediator variable distinction in social psychological research: Conceptual, strategic, and statistical considerations. Journal of Personality and Social Psychology, 51, 1173-1182. doi: 10.1037/0022-3514.51.6.1173

Brown, T.A., Cash, T.F., \& Mikulka, P.J. (1990). Attitudinal body image assessment: Factor analysis of the BodySelf Relations Questionnaire. Journal of Personality Assessment, 55, 135-144. doi: 10.1207/s15327752jpa5501\&2_13

Cash, T. F. (2000). User's manual for the Multidimensional Body-Self Relations Questionnaire. Unpublished manuscript, Old Dominion University, Norfolk, VA.

Cash, T. F., Melnyk, S. E., \& Hrabosky, J. I. (2004). The assessment of body image investment: An extensive revision of the appearance schemas inventory. International Journal of Eating Disorders, 35(3), 305-316. doi: 10.1002/eat.10264

Chernyak, Y., \& Lowe, M. R. (2010). Motivations for dieting: Drive for thinness is different from drive for objective thinness. Journal of Abnormal Psychology, 119, 276-281. doi: 10.1037/a0018398

Clark, M., Croghan, I., Reading, S., Schroeder, D., Stoner, S., Patten, C., \& Vickers, K. S. (2005). The relationship of body image dissatisfaction to cigarette smoking in college students. Body Image, 2, 263-270. doi: 10.1016/j.bodyim.2005.05.002

Crow, S., Peterson, C., Swanson, S., Raymond, N., Specker, S., Eckert, E., \& Mitchell, J. (2009). Increased mortality in bulimia nervosa and other eating disorders. The American Journal of Psychiatry, 166, 13421346. doi: 10.1176/appi.ajp.2009.09020247

Dallard, I., Cathebras, P., Sauron, C., \& Massoubre, C. (2001). Is cocoa a psychotropic drug? Psychopathologic study of a population of subjects self-identified as chocolate addicts. L'encéphale, 27, 181-186.

Finlayson, R., Kelly, I., \& Saklofske, D. (2002). Bulimic symptomatology, body-image, and personality characteristics of university men. Psychological Reports, 91, 496-502.

Fischer, J., \& Corcoran, K. J. (2007). Measures for clinical practice and research: A sourcebook. (4th ed.). NY. Oxford University Press.

Fisher, R. A. (1921). On the 'probable error' of a coefficient of correlation deduced from a small sample. Metron, 1, 3-32.

Goldfield, G., Blouin, A., \& Woodside, D. (2006). Body image, binge eating, and bulimia nervosa in male bodybuilders. The Canadian Journal of Psychiatry, 51, 160-168. doi: 10.1037/t00741-000

Green, S. P., \& Pritchard, M. E. (2003). Predicting body image dissatisfaction in adult men and

women. Social Behavior and Personality, 31, 215-222.

Hallsworth, L., Wade, T., \& Tiggemann, M. (2005). Individual differences in male body-image: An examination of self-objectification in recreational body builders. British Journal Of Health Psychology, 10, 453-465. doi: 10.1348/135910705X26966 
This is an author-produced, peer-reviewed version of this article. The final, definitive version of this document can be found online at Psychology of Men \& Masculinity, published by the American Psychological Association Copyright restrictions may apply. doi: 10.1037/a0032835

Hargreaves, D. A., \& Tiggemann, M. (2004). Idealized media images and adolescent body image: “comparing” boys and girls. Body Image, 1, 351-361. doi: 10.1016/j.bodyim.2004.10.002

Herpertz, S., Kocnar, M., \& Senf, W. (1997). Men with bulimia nervosa. Zeitschrift für Psychosomatische Medizin und Psychoanalyse, 43, 39-56.

Izgiç, F., Akyüz, G., Doğan, O., \& Kuğu, N. (2004). Social phobia among university students and its relation to selfesteem and body image. The Canadian Journal of Psychiatry, 49, 630-634. doi: 10.1037/t01038-000

Jacobi, L., \& Cash, T. F. (1994). In pursuit of the perfect appearance: Discrepancies among self-ideal perceptions of multiple physical attributes. Journal of Applied Social Psychology, 24, 379-396. doi: 10.1111/j.15591816.1994.tb00588.x

Joiner, T., Katz, J., \& Heatherton, T. (2000). Personality features differentiate late adolescent females and males with chronic bulimic symptoms. International Journal of Eating Disorders, 27, 191-197. doi: 10.1002/(SICI)1098-108X(200003)27:2<191::AID-EAT7>3.0.CO;2-S

Jones, W., \& Morgan, J. F. (2010). Eating disorders in men: A review of the literature. Journal of Public Mental Health, 9, 23-31. doi: 10.5042/jpmh.2010.0326

Jung, J., Forbes, G. B., \& Chan, P. (2010). Global body and muscle satisfaction among college men in the United States and Hong Kong-China. Sex Roles, 63, 104-117. doi: 10.1007/s11199-010-9760-z

Kyrejto, J. W., Mosewich, A. D., Kowalski, K. C., Mack, D. E., \& Crocker, P. E. (2008). Men's and women's drive for muscularity: Gender differences and cognitive and behavioral correlates. International Journal of Sport And Exercise Psychology, 6(1), 69-84. doi:10.1080/1612197X.2008.9671855

Leone, J. E., Sedory, E. J., \& Gray, K. A. (2005). Recognition and treatment of muscle dysmorphia and related body image disorders. Journal of Athletic Training, 40, 352-359.

McCabe, M., \& McGreevy, S. (2011). Role of media and peers on body change strategies among adult men: Is body size important? European Eating Disorders Review, 19, 438-446.

McCabe, M. P., Ricciardelli, L. A., Sitaram, G., \& Mikhail, K. (2006). Accuracy of body size estimation: Role of biopsychosocial variables. Body Image, 3(2), 163-171. doi:10.1016/j.bodyim.2006.01.004

McCreary, D. R., \& Sasse, D. K. (2000). An exploration of the drive for muscularity in adolescent boys and girls. Journal of American College Health, 48, 297-304. doi: 10.1080/07448480009596271

McCreary, D., Sasse, D., Saucier, D., \& Dorsch, K. (2004). Measuring the drive for muscularity: Factorial validity of the drive for muscularity scale in men and women. Psychology of Men \& Masculinity, 5, 49-58. doi: 10.1037/1524-9220.5.1.49

Mehler, P. S. (2011). Medical complications of bulimia nervosa and their treatments. International Journal of Eating Disorders, 44, 95-104.

Morgan, J. F. (2009). Crisis in masculinity leads to eating disorders in straight men. Press release from the Annual Meeting of the Royal College of Psychiatrists, Liverpool, UK. Available from: http://www.rcpsych.ac.uk/press/pressreleases-archive/2009/maleeatingdisorders.aspx (accessed September 2012).

Petrie, T., Greenleaf, C., Carter, J., \& Reel, J. (2007). Psychosocial correlates of disordered eating among male collegiate athletes. Journal of Clinical Sport Psychology, 1, 340-357.

Petrie, T. A., Greenleaf, C., Reel, J., \& Carter, J. (2009). Personality and psychological factors as predictors of disordered eating among female collegiate athletes. Eating Disorders: The Journal of Treatment \& Prevention, 17, 302-321. doi: 10.1080/10640260902991160

Pomery, C., \& Mitchell, J. E. (2001). Medical complications of anorexia nervosa and bulimia nervosa. In C. G. Fairburn, \& K. D. Brownell (Eds.), Eating disorders and obesity. A comprehensive handbook, 2nd ed. (pp. 278 -285). New York: Guilford Press.

Pritchard, M. E. (2008). Disordered eating in undergraduates: Does gender role orientation influence men and women the same way? Sex Roles, 59, 282-289. doi: 10.1007/s11199-008-9449-8

Ryan, T. A., \& Morrison, T. (2009). Factors perceived to influence young Irish men's body image investment: A qualitative investigation. International Journal Of Men's Health, 8(3), 213-234. doi:10.3149/jmh.0803.213.

Ryan, T. A., \& Morrison, T. G. (2011). Men's body image evaluation and investment: A review of key theoretical frameworks. In C. Blazina, D. S. Shen-Miller (Eds.), An international psychology of men: Theoretical advances, case studies, and clinical innovations (pp. 189-232). New York, NY US: Routledge/Taylor \& Francis Group.

Smith, M., \& Thelen, M. (1984). Development and validation of a test for bulimia. Journal of Consulting and Clinical Psychology, 52, 863-872. doi: 10.1037/0022-006X.52.5.863

Spann, N, \& Pritchard, M. E. (2010). Traditional and non-traditional male college students' attitudes on muscularity. Eating and Weight Disorders, 15, e90-92. 
This is an author-produced, peer-reviewed version of this article. The final, definitive version of this document can be found online at Psychology of Men \& Masculinity, published by the American Psychological Association Copyright restrictions may apply. doi: 10.1037/a0032835

Spoor, S. P., Bekker, M. J., Van Heck, G. L., Croon, M. A., \& Van Strien, T. (2005). Inner body and outward appearance: The relationships between appearance orientation, eating disorder symptoms, and internal body awareness. Eating Disorders: The Journal Of Treatment \& Prevention, 13, 479-490. doi: 10.1080/10640260500297267

Thelen, M. H., Farmer, J., Mann, L. M., \& Pruitt, J. (1990). Bulimia and interpersonal relationships: A longitudinal study. Journal of Counseling Psychology, 37, 85-90. doi: 10.1037/0022-0167.37.1.85

Thelen, M., Farmer, J., Wonderlich, S., \& Smith, M. (1991). A revision of the Bulimia Test: The BULIT-R. Psychological Assessment, 3, 119-124. doi: 10.1037/1040-3590.3.1.119

Tong, J., Miao, S., Wang, J., Zhang, J., Wu, H., Li, T., \& Hsu, L. (2005). Five cases of male eating disorders in Central China. International Journal Of Eating Disorders, 37, 72-75. doi: 10.1002/eat.20061

Wojtowicz, A., \& von Ranson, K. (2006). Psychometric evaluation of two scales examining muscularity concerns in men and women. Psychology of Men \& Masculinity, 7, 56-66. doi: 10.1037/1524-9220.7.1.56 


\section{Table 1}

\section{Sex Differences in Key Variables}

\begin{tabular}{lllll}
\hline \multicolumn{1}{l}{ Females } & \multicolumn{2}{l}{ Males } & \\
Variable & $M \quad(S D)$ & $M \quad(S D)$ & $F(1,271)$ & $\eta^{\underline{2}}$ \\
\hline Bulimia & $57.47(17.43)$ & $55.51(17.82)$ & 2.78 & .01 \\
DFM & $22.03(6.94)$ & $30.58(10.44)$ & $59.98 * * *$ & .18 \\
OvPreocc & $2.79(0.96)$ & $2.00(0.85)$ & $43.60^{* * *}$ & .14 \\
Wght Class & $3.27(0.58)$ & $2.94(0.69)$ & $19.34^{* * *}$ & .07 \\
App Eval & $3.29(0.75)$ & $3.46(0.77)$ & 2.35 & .01 \\
App Orient & $3.51(0.62)$ & $3.12(0.62)$ & $20.39 * * *$ & .07 \\
\hline
\end{tabular}

Note. DFM=Drive for Muscularity (higher scores=greater drive for muscularity), Ov. Preocc=Preoccupation with becoming overweight (higher scores=more preoccupation), Wght Class=self-classified weight status (e.g., very underweight to very overweight; higher scores=think they are more overweight), App Eval=Appearance Evaluation (higher scores=more positive evaluation of their own appearance), App Orient=Appearance Orientation (higher scores=more focused on their appearance); ${ }^{* * *} p<.001$ 


\section{Table 2}

\section{Summary of Intercorrelations between Measures as a Function of Sex}

\begin{tabular}{|c|c|c|c|c|c|c|}
\hline Measure & 1 & 2 & 3 & 4 & 5 & 6 \\
\hline 1. Bulimia & -- & .13 & $.60 * * *$ & $.33 * * *$ & $-.47 * * *$ & $.31 * * *$ \\
\hline 2. DFM & $.42 * * *$ & --- & $.17^{*}$ & .07 & -.06 & $.16^{*}$ \\
\hline 3. OvPreocc & $.42 * * *$ & $.26^{*}$ & -- & $.41 * * *$ & $-.46 * * *$ & $.49 * * *$ \\
\hline 4. Wght Class & $.38 * * *$ & .19 & $.52 * * *$ & -- & $-.57 * * *$ & $.17^{*}$ \\
\hline 5. App Eval. & $-.25 *$ & -.11 & $-.39 * * *$ & $-.43 * * *$ & -- & $-.14^{*}$ \\
\hline 6. App Orien. & $.29 * *$ & $.37 * * *$ & $.50 * * *$ & $.31 * *$ & -.12 & -- \\
\hline
\end{tabular}

Note. Intercorrelations for female participants $(n=197)$ are presented above the diagonal; intercorrelations for male participants $(n=84)$ are presented below the diagonal. DFM=Drive for Muscularity (higher scores=greater drive for muscularity), OvPreocc=Preoccupation with becoming overweight (higher scores=more preoccupation), Wght Class=self-classified weight status (e.g., very underweight to very overweight; higher scores=think they are more overweight), App Eval=Appearance Evaluation (higher scores=more positive evaluation of their own appearance), App Orien=Appearance Orientation (higher scores=more focused on their appearance)

$* p<.05$

$* * p<.01$

$* * * p \leq .001$ 
This is an author-produced, peer-reviewed version of this article. The final, definitive version of this document can be found online at Psychology of Men \& Masculinity, published by the American Psychological Association Copyright restrictions may apply. doi: $10.1037 / \mathrm{a} 0032835$

Table 3

Summary of Hierarchical Regression for Variables Predicting Bulimic Symptomology

\section{Variable}

Step 1

Sex

Age

Step 2

Sex

Age

DFM

OvPreocc

Wght Class

App Eval

App Orient

Step 3

Sex

Age

DFM

OvPreocc

Wght Class
$B \quad S E B \quad \beta$

$t$

$p r$

.01

1.43

$\begin{array}{lllll}-1.27 & .76 & -.10 & 1.67 & -.10\end{array}$

$\begin{array}{lllll}.11 & .17 & .04 & .63 & .04\end{array}$

$R^{2} \underline{\Delta} \quad F \Delta \quad d f \Delta(1,2)$

$.2821 .19 * * * 5,266$

$\begin{array}{lllll}.01 & .82 & .01 & .02 & .01 \\ .06 & .15 & .02 & .38 & .02\end{array}$

$\begin{array}{lllll}.08 & .04 & .14 & 2.27 * & .14\end{array}$

$\begin{array}{lllll}1.61 & .41 & .29 & 3.93 * * * & .23\end{array}$

$\begin{array}{lllll}.35 & .58 & .04 & .61 & .04\end{array}$

$\begin{array}{lllll}-1.84 & .48 & -.25 & -3.87 * * * & -.23\end{array}$

$\begin{array}{lllll}.64 & .55 & .07 & 1.18 & .07\end{array}$ 


\begin{tabular}{lccccc} 
App Eval & -2.15 & .59 & -.29 & $-3.67 * * *$ & -.22 \\
App Orient & .85 & .64 & .10 & 1.32 & .08 \\
Sex*DFM & .10 & .08 & .11 & 1.28 & .08 \\
Sex*OvPreocc & -1.53 & .97 & -.14 & -1.58 & -.10 \\
Sex*WghtClass & 1.60 & 1.19 & .11 & 1.34 & .08 \\
Sex*AppEval & .74 & .99 & .06 & .74 & .05 \\
Sex*AppOr & -.88 & 1.22 & -.06 & -.72 & -.05 \\
\hline
\end{tabular}

Note. DFM=Drive for Muscularity (higher scores=greater DFM), OvPreocc=Preoccupation with becoming overweight (higher scores=more preoccupation), Wght Class=self-classified weight status (e.g., very underweight to very overweight; higher scores=think they are more overweight), App Eval=Appearance Evaluation (higher scores=more positive evaluation of their own appearance), App Orien=Appearance Orientation (higher scores=more focused on their appearance)

${ }^{*} p<.05$

$* * p<.01$

$* * * p \leq .001$ 